American Journal of Pharmaceutical Education 2020; 84 (2) Article 7232.

\title{
BRIEF
}

\section{Impact of Curricular Integration Between Patient Care Laboratory and Introductory Pharmacy Practice Experience on Documentation}

\author{
Holly Divine, PharmD, ${ }^{a}$ Mikael Jones, PharmD, ${ }^{a}$ Yevgeniya Gokun, MS, ${ }^{b}$ Tera McIntosh, PharmD ${ }^{\mathrm{a}}$ \\ ${ }^{a}$ University of Kentucky College of Pharmacy, Lexington, Kentucky \\ ${ }^{\mathrm{b}}$ University of Arkansas for Medical Sciences, Little Rock, Arkansas \\ Submitted June 21, 2018; accepted July 31, 2019; published February 2020.
}

Objective. To assess the impact of curricular changes made through vertical integration between Patient Care Laboratory and Introductory Pharmacy Practice Experience (IPPE) courses on documentation outcomes.

Methods. Curricular changes to address student pharmacist documentation deficiencies were developed by laboratory and experiential faculty members. A documentation activity using subjective, objective, assessment, plan (SOAP) notes completed in one IPPE rotation block, pre-intervention, were graded and compared to SOAP notes from the same IPPE rotation block in the subsequent year, post-intervention, using a standard checklist. Chi square test (or Fisher exact test when appropriate) was used to evaluate the relationship between each question's score and different timepoints. Wilcoxon rank sum test was used to compare total scores between the two groups of students.

Results. Significant improvement among student pharmacists' SOAP note scores were observed in the post-intervention cohort $(n=52)$ compared to pre-intervention cohort $(n=52)$ following curricular changes. Specific SOAP note components that revealed significant improvements between years were drug therapy problem identified, proposed drug therapy problem resolution, follow-up plan identified, overall impression, and addressing a pharmacist-specific intervention.

Conclusion. Collaboration between laboratory and experiential education faculty members are integral to the identification of gaps in student pharmacists' application of simulated activities into actual experiences and in the achievement of educational outcomes. Curricular quality improvements can be implemented and assessed quickly through vertically integrated courses.

Keywords: documentation, curricular integration, introductory pharmacy practice experience, patient care laboratory, quality improvement

\section{INTRODUCTION}

Integrated curricula in health care professions education has gained worldwide momentum in an effort to promote "change agents" by combining both knowledgebased and skills-based content to meet healthcare needs. ${ }^{1}$ In pharmacy specifically, the Accreditation Council for Pharmacy Education (ACPE) Standards 2016 emphasize the intentional sequence of pharmacy curricula to promote integration in curricular design and delivery. ${ }^{2} \mathrm{~A}$ proposed working definition of integration introduced by Kerr and colleagues is a "multi-faceted term describing a curriculum design which may be defined by model (horizontal, vertical, spiral), theme (systems-based, stages of life, topic, cross-cutting theme) and integrative teaching

Corresponding Author: Holly Divine, University of Kentucky College of Pharmacy, 789 S. Limestone, 114W, Lexington, KY 40536-0596. Tel: 859-323-9332. Email: holly.divine@uky.edu and learning approach (problem-based, case-based, experiential, enquiry-based, team-based learning, interprofessional education) and level of integration." ${ }^{1}$ Horizontal integration, the most commonly described model in the literature, typically connects various disciplines with regards to the same concept, such as between basic and clinical sciences, while vertical integration, the second most common model, involves either curricular progression over time, such as from professional year one through professional year four, or connection between didactic or classroom learning to experiential, authentic real-world application. ${ }^{1,3,4,5}$

Although the idea of an integrated curriculum has been adopted by multiple disciplines, evidence on the benefits of integration remains sparse and mostly limited to perception data. ${ }^{1}$ Various horizontal integration implementation strategies in pharmacy education have been reported, but there are fewer examples of vertically integrated courses, specifically between didactic and 


\section{American Journal of Pharmaceutical Education 2020; 84 (2) Article 7232.}

experiential teaching and learning approaches. ${ }^{6-15}$ Measures of integration success using specific activities and assignments to connect classroom learning to experiential courses have largely been documented by assignment completion rates and preceptor and/or student pharmacist evaluations of integration success. ${ }^{6,16,17}$

The University of Kentucky (UK) College of Pharmacy's pre-advanced pharmacy practice experience (APPE) curriculum includes a six-semester Patient Care Laboratory course sequence and two introductory pharmacy practice experiences (IPPEs). Students are divided into small groups of approximately 32 students to attend the Patient Care Laboratory course. The IPPEs are split into two rotations, with the first one, community pharmacy, held in the summer session following the first professional year (P1), and the second one, institutional pharmacy, held in the summer session following the second professional year (P2). Each session is divided into as many as three four-week sections to accommodate site and preceptor capacities. One faculty member served as the director of the Patient Care Laboratory course and experiential education. Having one person oversee the laboratory and experiential courses facilitated collaboration, consistency, and curricular integration, specifically with bridging simulated activities with real-world practice experiences. An in-depth understanding of the practice sequence and concepts taught in each individual course was achieved through annual planning retreats with the director and each faculty member involved in the courses. The director and the course coordinators for all laboratory and experiential education courses participated in regular meetings, thus creating frequent opportunities for bidirectional communication and collaboration to develop an integrated practice curriculum between college-based and practice site-based courses. This continual planning and communication among faculty members resulted in the development of IPPE activities that reinforced and complemented the Patient Care Laboratory activities in the preceding semesters. All faculty members in the sequence contributed to developing course-level competencies to ensure achievement of curricular educational outcomes.

The college, using the Center for the Advancement of Pharmacy Education (CAPE) Educational Outcomes 2013, identified the documentation of patient care as a key professional outcome. ${ }^{18}$ Subjective, objective, assessment, plan (SOAP) notes are one way to document pharmacist interventions in patient care activities and are widely accepted as an interprofessional communication and documentation tool. Student pharmacists are introduced to SOAP notes in the Patient Care Laboratory course in the fall semester of the P2 year, with reinforcement throughout the spring semester of the P2 year and the third professional year (P3). One assignment in the institutional IPPE requires the student pharmacist to identify and resolve a drug therapy problem and create a SOAP documentation of the encounter. During this IPPE activity, a potential deficiency in student pharmacists' ability to appropriately document was identified by the IPPE course coordinator, specifically with assessment and plan sections. Upon review of IPPE SOAP notes, student pharmacists appeared to be documenting the entire patient hospital admission as opposed to focusing on the pharmacist encounter of identifying and resolving a drug therapy problem. The notes seemed to lack clarity and were not concise. Experiential education faculty members brought the deficiency to the attention of the Patient Care Laboratory course faculty members in a regular team meeting. These deficiencies had not been previously identified during course documentation activities prior to the IPPE. In this paper, we describe the new and revised integrated curricular strategies that the course and IPPE faculty members implemented to address the documentation concerns identified in the institutional IPPE and report the impact of these interventions on the learning outcomes. The objective of this study was to assess the impact of curricular changes made through vertical integration between the Patient Care Laboratory course and IPPE courses on student documentation outcomes.

\section{METHODS}

Specific curricular changes to improve SOAP documentation outcomes were implemented in the curriculum. These included revisions in the Patient Care Laboratory documentation activities in the spring semester preceding the summer institutional IPPE and the Patient Care Laboratory course in the fall semester after the completion of the IPPE. Previously, in the spring semester prior to the IPPE, students participated in a simulated patient encounter that required them to create a SOAP note of the encounter "from scratch" based on previously defined SOAP components taught in preparation seminars for the Patient Care Laboratory course. Course faculty members provided individual written recommendations for improvement on each submission for feedback. The revised course activity in the spring included creation of a standardized SOAP documentation form to help students visualize the required components and an instructor-guided SOAP documentation activity. Additionally, students viewed a recorded simulated encounter during a Patient Care Laboratory session, wrote a SOAP note of the encounter, and used a peer-grading system within their previously assigned groups broken into smaller subgroups to review and discuss the various sections of the note. 


\section{American Journal of Pharmaceutical Education 2020; 84 (2) Article 7232.}

Students then shared the results of their peer-grading discussions with the entire class and the instructor for further clarification and review. Additional SOAP note assignments were also incorporated into a variety of Patient Care Laboratory activities throughout the semester.

The revised fall semester Patient Care Laboratory activities included a new recorded simulated encounter activity, similar to the one in the spring semester, to reinforce documentation skills. Additionally, two de-identified IPPE notes from the summer experience were provided to each previously assigned group of students for review. The groups made recommendations on how to improve and revise each note.

The SOAP notes completed in the pre-intervention class (Class of 2012) by student pharmacists during one section of the institutional pharmacy IPPE were compared to the SOAP notes completed the following year by student pharmacists in the post-intervention class (Class of 2013) in the same section of the institutional pharmacy IPPE. Notes were compared to measure the impact of curricular changes targeting documentation. This study was granted exempt status by the university's institutional review board.

The following student pharmacist demographic variables were collected for the overall class (not at the individual student level) to compare students in the preintervention IPPE to the students in the post-intervention IPPE: age, gender, ethnicity, in-state residency status, spring semester (prior to summer IPPE), GPA, and cumulative GPA. A standardized checklist was created to assess the presence of 18 essential SOAP note components and general components. The following are examples of these components: "Subjective: chief complaint; Objective: relevant medication included; Assessment: drug therapy problem identified; Plan: proposed drug therapy problem resolution (include specific drug, dose, frequency)"; and "general: overall impression (clear, concise, easy to read, etc)." The SOAP notes were evaluated and one point was assigned for each correctly included component for a total potential score of 18 . The checklist was validated by choosing a random sample of 10 notes graded by two faculty members and one APPE student. All discrepancies in scoring were discussed and consensus was reached to ensure consistent grading of the study sample. One evaluator graded all SOAP notes. The evaluator was blinded to the individual student and class. Each checklist question was coded as $1=$ satisfactory or $0=$ non-satisfactory. Total scores were calculated as the sum of the questions' results for each student.

The chi square test (or the Fisher exact test when appropriate) was used to evaluate the relationship between each discrete variable and two class years. Demographic continuous variables that followed normal distribution were analyzed using two-sample $t$ test, and the Wilcoxon signed rank sum test was used to compare the overall total score between the two groups of students. Students' ethnicity was categorized as White, Black, or other. In-state residency status was analyzed as binary variable (resident vs nonresident). The statistical significance level was set at 0.05 . The data were analyzed using SAS, version 9.3 (SAS Institute Inc., Cary, NC).

\section{RESULTS}

Fifty-two SOAP notes from the pre-intervention IPPE cohort were scored and compared with 52 SOAP notes from the post-intervention IPPE cohort. Table 1 shows a comparison of demographic variables between students in the two class years. Pre- and post-intervention student pharmacist characteristics were similar except for gender and in-state residency status. There were more male students in the pre-intervention IPPE compared to the post-intervention IPPE $(44 \%$ vs $21 \%, p<.05)$ and more in-state residents in the pre-intervention IPPE compared to the post-intervention IPPE ( $96 \%$ vs $75 \%$, $p=.004)$.

A comparison of each of the 18 SOAP note components between the two years is provided in Table 2 . There were no significant improvements in the individual SOAP components within the subjective and objective categories. In the assessment section, there was a significant improvement in drug therapy problem (DTP) Identification in the post-intervention IPPE $(p<.05)$. Significant improvements occurred in the plan section for both documentation of the Proposed DTP Resolution, $(p<.05)$ and Follow-Up Plan Identified $(p=.003)$. In the general category, a significant improvement in the SOAP notes was seen in the post-intervention IPPE $(p<.05)$ for the item "overall good impression," which evaluated the note for overall clarity, conciseness, and ease of reading. Finally, the post-intervention cohort were more likely to address a specific pharmacist intervention $(p<.05)$.

The median as well as interquartile range (IQR) for the overall total SOAP score were also compared between the two years. The pre-intervention median score was 13 with an interquartile range of 11-15. The post-intervention median score was 15 with an interquartile range of 13-17. There was a significant difference in the total IPPE SOAP note assignment score between pre- and postcurricular intervention $(p<.007)$.

\section{DISCUSSION}

This study demonstrates how collaboration of faculty members who coordinate vertically integrated courses can address gaps in students' educational outcomes. Vertical integration strategies developed by faculty 
Table 1. Characteristics of Student Pharmacists Enrolled in an Introductory Pharmacy Practice Experience Before and After Curricular Changes Were Made to Improve Documentation Skills

\begin{tabular}{|c|c|c|c|}
\hline Variable & $\begin{array}{c}\text { Class Years } \\
\text { Pre-Intervention } \\
(n=52)(\%)\end{array}$ & $\begin{array}{l}\text { Post-Intervention } \\
(n=52)(\%)\end{array}$ & $p$ Value \\
\hline \multicolumn{4}{|l|}{ Age } \\
\hline Mean (SD) & $24.5(3.0)$ & $23.6(1.7)$ & .06 \\
\hline Gender & & & .01 \\
\hline Male & $23(44)$ & $11(21)$ & \\
\hline White & $43(83)$ & $41(79)$ & \\
\hline Black & $3(6)$ & $3(6)$ & \\
\hline Other & $6(12)$ & $8(15)$ & \\
\hline Residency & & & .004 \\
\hline Resident & $50(96)$ & $39(75)$ & \\
\hline Cumulative GPA & & & .14 \\
\hline Mean (SD) & $3.28(0.45)$ & $3.40(0.40)$ & \\
\hline
\end{tabular}

members in these Patient Care Laboratory and IPPE courses led to quickly recognizing, responding, and resolving student deficiencies in one key educational outcome focused on documentation resulting in general
SOAP note improvements as well as improvements in the specific assessment and plan areas (Table 2). Although the study was not designed to determine which specific activities (eg, guided instruction, peer-grading, and

Table 2. Comparison of Student Pharmacists' Scores on Documenting a Patient Encounter Before and After Curricular Intervention

\begin{tabular}{|c|c|c|c|c|c|}
\hline $\begin{array}{l}\text { SOAP } \\
\text { Category }\end{array}$ & $\begin{array}{c}\text { Item } \\
\text { Number }\end{array}$ & SOAP Component & $\begin{array}{l}\text { Pre-Intervention } \\
\text { Score (\%) }\end{array}$ & $\begin{array}{l}\text { Post-Intervention } \\
\text { Score (\%) }\end{array}$ & $p$ Value \\
\hline \multirow[t]{4}{*}{ Subjective } & 1 & $\begin{array}{l}\text { Patient Identifier Included (age, sex at } \\
\text { minimum) }\end{array}$ & 92 & 96 & .68 \\
\hline & 2 & Chief Complaint or Reason for Hospitalization & 100 & 100 & N/A \\
\hline & 3 & $\begin{array}{l}\text { Brief Summary of Current Condition or } \\
\text { Hospital Stay to Date }\end{array}$ & 83 & 79 & .62 \\
\hline & 4 & Excluded $\mathrm{O} / \mathrm{A} / \mathrm{P}$ Info & 98 & 92 & .36 \\
\hline \multirow[t]{3}{*}{ Objective } & 5 & Relevant Medication Included & 89 & 85 & .57 \\
\hline & 6 & Key labs with Date & 25 & 35 & .28 \\
\hline & 7 & Excluded S/A/P Info & 94 & 98 & .62 \\
\hline \multirow[t]{3}{*}{ Assessment } & 8 & Indication (Medical Condition) Identified & 73 & 83 & .24 \\
\hline & 9 & DTP Identified & 40 & 64 & $.02^{\mathrm{a}}$ \\
\hline & 10 & Excluded S/O/P Info & 67 & 77 & .27 \\
\hline \multirow[t]{5}{*}{ Plan } & 11 & Indication Included & 50 & 56 & .56 \\
\hline & 12 & Goal of Therapy Included & 37 & 46 & .32 \\
\hline & 13 & $\begin{array}{l}\text { Proposed DTP Resolution (includes specific } \\
\text { drug, dose, frequency) }\end{array}$ & 54 & 75 & $.02^{\mathrm{a}}$ \\
\hline & 14 & F/U Plan Identified & 64 & 89 & $.003^{\mathrm{a}}$ \\
\hline & 15 & Excluded S/O/A Info & 98 & 100 & $p>.99$ \\
\hline \multirow[t]{3}{*}{ General } & 16 & Appropriate Grammar/Spelling & 90 & 98 & .21 \\
\hline & 17 & $\begin{array}{l}\text { Overall Good Impression (clear, concise, easy } \\
\text { to read, etc.) }\end{array}$ & 62 & 81 & $.03^{\mathrm{a}}$ \\
\hline & 18 & Addresses a Specific Pharmacist Intervention & 83 & 98 & $.02^{\mathrm{a}}$ \\
\hline
\end{tabular}

Abbreviations: SOAP = subjective, objective, assessment, plan; DTP=drug therapy problem; $\mathrm{F} / \mathrm{U}=$ follow-up

${ }^{a}$ Significant difference $(p<.05)$ 


\section{American Journal of Pharmaceutical Education 2020; 84 (2) Article 7232.}

recorded simulated encounters with documentation activities) were instrumental in the improved outcomes, the close integration of the faculty members involved in each of these courses led to identifying an area of concern and quickly bringing increased attention to a key area of teaching (documentation) within the Pharmacists' Patient Care Process to address the concern.

Colleges and schools of pharmacy have reported the difficulty not only in closing the feedback loop by using assessment data collected to make curricular change but also in the timeliness of that change. ${ }^{20,21}$ The ability to fully implement the loop of quality improvement in a short period through this course-level assessment emerged as an additional strength of the continual collaboration between Patient Care Laboratory course faculty and IPPE faculty members at the University of Kentucky. The routine collaboration allowed faculty members to identify and quickly share gaps in student pharmacists' application of a key educational outcome from didactic to real-world practice. Immediately, faculty members collaborated to make bidirectional course revisions and formulated a plan to assess those revisions at the course level.

No significant improvements were seen between pre-intervention and post-intervention cohorts for subjective or objective areas of the SOAP notes; however, six of the seven variables in these areas had $80 \%$ or above scores in the pre-intervention period, leaving less margin for performance improvements. Perhaps, the pre-APPE courses in the first two years of the curriculum prepared students well for collecting information but did not fully instruct students on how to complete the assessment and plan portions of the note. The deficiencies observed by the IPPE faculty members included concerns about documentation of the identification and resolution of a medication-related problem (ie, a pharmacist intervention). The new activities that were developed in the Patient Care Laboratory course to address the concerns provided more opportunities for students to practice their documentation skills, specifically through the recorded simulated encounter where students could observe an encounter and determine what information should be placed in the correct sections of the note. It also increased the number of opportunities during the Patient Care Laboratory for documentation and focused more on the assessment and plan areas, which had the greatest opportunities for improvement pre- and post-intervention.

One limitation of this study was the assessment of only one educational outcome and associated activity within the vertically integrated course sequence. Although the documentation was the focus of this intervention, other educational outcomes may benefit from the vertical integration and feedback strategies used in this study. Another limitation lies in the characteristic differences between the two groups of student pharmacists. The two groups differed significantly with regards to gender and in-state residency status; however, it is unclear how these characteristic differences may contribute to differences in SOAP note scores.

Faculty members bear the responsibility of ensuring that the student experience is integrated. ${ }^{3,5,19}$ This responsibility lies not only in a solid curricular design, but also in an in-depth understanding of the curriculum, of where their course fits in the curricular plan, and what other faculty members are teaching. Lack of time, insufficient effort, and limited opportunity for interaction between faculty members have been identified as obstacles to curricular integration. ${ }^{3}$ The administrative appointment of a single director for the Patient Care Laboratory course and IPPE courses created intentional opportunities for faculty collaboration to achieve successful vertical integration between didactic learning and real-world application as this study demonstrates. In pharmacy schools where these courses have different administrators, intentional planning efforts for course development and quality assessments between simulated and experiential faculty members may be warranted to ensure the integration remains successful.

The UK College of Pharmacy implemented a reformed curriculum beginning with the class of 2020 . Building upon the successes of the integration between the Patient Care Laboratory and IPPE coursework in the legacy curriculum, a new six-semester course sequence entitled Patient-Centered Care Experience $(\mathrm{PaCE})$ integrates simulated laboratory activities, experiential education activities (IPPEs), and community service learning activities. Faculty members, including those who were a part of the model described above, continue to engage in formal collaboration to design and implement new introductory practice experiences simultaneously with simulated laboratory coursework. Faculty members implementing the $\mathrm{PaCE}$ sequence will continue to assess quality of educational outcomes and course revisions through continuous quality improvement based on the quality improvement model demonstrated in this documentation activity.

\section{CONCLUSION}

This study demonstrates that collaborative efforts among faculty members to identify and address educational gaps across progressive coursework in a pharmacy curriculum, specifically between a Patient Care Laboratory course and an IPPE, can lead to improvements in educational outcomes. Curricular quality improvements can be implemented and assessed quickly through vertically integrated courses. This study contributes to the 


\section{American Journal of Pharmaceutical Education 2020; 84 (2) Article 7232.}

current literature regarding the effectiveness of an integrated curriculum, specifically with vertical models used within experiential coursework; however, further scholarship of teaching and learning to demonstrate the effectiveness of curricular integration in pharmacy education should be explored.

\section{ACKNOWLEDGMENTS}

The authors would like to acknowledge Tyler Lanham, PharmD for providing SOAP assessments and data collection.

\section{REFERENCES}

1. Kerr A, O'Connor H, Pawlikowska T, Gallagher P, Strawbridge J. A scoping review of health professional curricula: Implications for developing integration in pharmacy. Res Social Admin Pharm. 2020;16(1):1-16. https://doi.org/10.1016/j.sapharm.2019. 03.005 .

2. Accreditation Council for Pharmacy Education. Accreditation Standards and Key Elements for the Professional Program in Pharmacy Leading to the Doctor of Pharmacy Degree ("Standards 2016”). Published February 2015. https:/www.acpe-accredit.org/ pdf/Standards2016FINAL.pdf. Accessed February 19, 2020. 3. Pearson ML, Hubball HT. Curricular integration in pharmacy education. Am J Pharm Educ. 2012;76(10):Article 204.

4. Kerr RA. Curricular integration to enhance educational outcomes. Pharmacotherapy 2000;20(10 Pt 2):292S-296S

5. Ratka A. Integration as a paramount educational strategy in academic pharmacy. Am J Pharm Educ. 2012;76(2):Article 19. 6. Karimi R, Arendt CS, Cawley P, et al. Learning bridge: curricular integration of didactic and experiential education. Am J Pharm Educ. 2010;74(3):Article 48.

7. Dirks-Naylor AJ, Wright N, Alston GL. Development and assessment of a horizontally integrated biological sciences course sequence for pharmacy education. Am J Pharm Educ.

2015;79(6):Article 89.
8. Harrold MW, McFalls MA. A pharmacy practice laboratory exercise to apply biochemistry concepts. Am J Pharm Educ. 2010;74(8):Article 144. 9. Witt-Enderby PA, McFalls-Stringert MA. The integration of basic cell biology concepts into the practice of pharmacy. Am J Pharm Educ. 2004;68(2):Article 40.

10. Marshall LL, Nykamp D. Active-learning assignments to integrate basic science and clinical course material. Am J Pharm Educ. 2010;74(7):Article 119.

11. Stewart AL, Buckner IS, Wildfong PL. A shared assignment to integrate pharmaceutics and pharmacy practice course concepts. Am J Pharm Educ. 2011;75(3); Article 44.

12. Kolluru S, Roesch DM, de la Fuente AA. A multi-instructor, team-based, active-learning exercise to integrate basic and clinical sciences content. Am J Pharm Educ. 2012;76(2);Article 33.

13. Albano CB, Brown W. Integration of physical assessment within a pathophysiology course for pharmacy. Am J Pharm Educ. 2012;76(1):Article 14.

14. Black EP, Policastri A, Garces H, et al. A pilot common reading experience to integrate basic and clinical sciences in pharmacy education. Am J Pharm Educ. 2012;76(2):Article 25.

15. Wensel TM, Broeseker AE, Kendrach MG. Design, implementation, and assessment of an integrated pharmacy applications course series. Curr Pharm Teach Learn. 2014;6(5):706-715.

16. Krueger JL. Pharmacy students' application of knowledge from the classroom to introductory pharmacy practice experiences. Am J Pharm Educ. 2013;77(2):Article 31.

17. Wuller WR, Luer MS. A sequence of introductory pharmacy practice experiences to address the new standards for experiential learning. Am J Pharm Educ. 2008;72(4);Article 73.

18. Medina MS, Plaza CM, Stowe CD, et al. Center for the advancement of pharmacy education 2013 educational outcomes. Am J Pharm Educ. 2013;77(8); Article 162.

19. Alsharif NZ. Curriculum integration: a self-driven continuum. Am J Pharm Educ. 2014;78(1):Article 2.

20. Ried LD. A model for curricular quality assessment and improvement. Am J Pharm Educ. 2011;75(10):Article 196. 21. Piascik P, Bird E. Creating and sustaining a culture of assessment. Am J Pharm Educ. 2008;72(5):Article 97. 